\title{
Поверхностные токи и спонтанный магнетизм в гальваномагнитных свойствах низкоконцентрированных электронных систем донорных примесей переходных элементов
}

\author{
Окулов В.И. \\ ИФМ им. М.Н. Михеева УрО РАН, 620108, ул. С. Ковалевской, 18, Екатеринбург
}

DOI 10.34077/Semicond2019-330

Исследования магнетизма [1] и квантовых гальваномагнитных явлений [2-4] в электронной системе полупроводника с донорными примесями низкой концентрации, отвечающей отсутствию проявления межпримесного взаимодействия, доказали существование спонтанной спиновой поляризации такой системы благодаря гибридизации электронных состояний в полосе проводимости кристалла. В настоящем докладе на основе развития изложенных в сообщении [5] представлений о проявлениях спонтанных токов проводимости в термодинамике магнетизма электронов рассмотрены предсказанные вклады равновесных поверхностных токов в холловскую и поперечную компоненты тензора сопротивления изучаемых низкоконцентрированных систем. Эти вклады приповерхностных токовых слоёв имеют линейные зависимости от напряжённости магнитного поля, в своих коэффициентах отражают форму и структуру поверхности кристалла и тем самым дают возможность объяснить наблюдавшиеся в экспериментах именно такого рода закономерности.

Для объяснения существования поверхностных токов нужно прежде всего принять во внимание тот факт, что холловское сопротивление электронной системы содержит часть, происходящую от тока локально равновесного состояния, рассматриваемого как равновесное в электрическом поле, создаваемом источником тока. При этом оказывается, что и в термодинамически равновесном состоянии без электрического поля существует равновесные не только токи намагничения, но и токи проводимости. В однородной системе неоднородности распределения электронной плотности и равновесные токи концентрируется в приповерхностном слое, который формируется неоднородным приграничным распределением электронной плотности, атомного масштаба, и масштаба, определяемого электронными состояниями в магнитном поле, модифицированными границей. В таком слое образуется градиент электронного давления, направленный по нормали к границе, который и создаёт поверхностный недиссипативный ток проводимости. Этот ток добавляется к локально равновесному току при подключении поля источника тока и приводит кроме того к дополнительному недиссипативному вкладу в магнитосопротивление. Такой поверхностный вклад в магнитосопротивление может объяснить часто наблюдающуюся и считающуюся трудно объяснимой линейную зависимость. Другие закономерности, связанные с проявлениями поверхностных вкладов, состоят в зависимости гальваномагнитных эффектов от структуры поверхности и от формы границ. В докладе обсуждается также влияние на поверхностные токи спонтанной спиновой поляризации электронной системы.

Работа выполнена в рамках государственного задания по теме «Электрон» № AAAA-A18118020190098-5 и проекту № 18-10-2-6 Программы УрО РАН.

[1] Т.Е. Говоркова, В.И. Окулов. ФНТ 44, 1562 (2018).

[2] А.Т. Лончаков, В.И. Окулов, Т.Е. Говоркова и др. Письма в ЖЭТФ 96, 444 (2012).

[3] A.T. Lonchakov, V.I. Okulov et al., Solid State Phenomena 233-234, 456 (2015).

[4] В.И. Окулов, Е.А. Памятных, А.Т. Лончаков. ФНТ 40, 1322 (2014).

[5] Vsevolod Okulov, Evgeny Pamyatnykh. EPJ Web of Conferences 185, 1017 (2018). 